\title{
Clinical value of ambulatory blood pressure in pediatric patients after renal transplantation
}

\author{
Rafael T. Krmar ${ }^{1}$ Jorge R. Ferraris ${ }^{2}$
}

Received: 1 June 2017 / Revised: 27 July 2017 / Accepted: 31 July 2017 /Published online: 25 August 2017

(C) The Author(s) 2017. This article is an open access publication

\begin{abstract}
Hypertension is a highly prevalent co-morbidity in pediatric kidney transplant recipients. Undertreated hypertension is associated with cardiovascular complications and negatively impacts renal graft survival. Thus, the accurate measurement of blood pressure is of the utmost importance for the correct diagnosis and subsequent management of post-renal transplant hypertension. Data derived from the general population, and to a lesser extent from the pediatric population, indicates that ambulatory blood pressure monitoring (ABPM) is superior to blood pressure measurements taken in the clinical setting for the evaluation of true mean blood pressure, identification of patients requiring antihypertensive treatment, and in the prediction of cardiovascular outcome. This Educational Review will discuss the clinical value of ABPM in the identification of individual blood pressure phenotypes, i.e., normotension, new-onset hypertension, whitecoat hypertension, masked hypertension, controlled blood pressure, and undertreated/uncontrolled hypertension in pediatric kidney transplant recipients. Finally, we examine the utility of performing repeated ABPM for treatment monitoring of post-renal transplant hypertension and on surrogate markers related to relevant clinical cardiovascular outcomes. Taken
\end{abstract}

This article is part of the topical collection on "What's New in Renal Transplantation?"

Rafael T. Krmar

rafael.krmar@ki.se

Jorge R. Ferraris

jorge.ferraris@hospitalitaliano.org.ar

1 Department of Physiology and Pharmacology (FYFA), Karolinska Institute, C3, Nanna Svartz Väg 2, 17177 Stockholm, Sweden

2 Departamento de Pediatría, Hospital Italiano de Buenos Aires, Juan D. Perón 4190, C1199ABB C.A.B.A, Código, Argentina together, our review highlights the clinical value of the routine use of ABPM as a tool for identifying and monitoring hypertension in pediatric kidney transplant recipients.

Keywords Renal transplantation · Children · Hypertension · Ambulatory blood pressure monitoring

\section{Introduction}

Hypertension is a central risk factor for the development of cardiovascular disease and a major cause of morbidity and mortality in the general adult population [1-3]. Hypertensive children with underlying chronic kidney disease are at increased risk for cardiovascular disorders $[4,5]$. Hypertension is also a highly prevalent co-morbidity following renal transplantation in children and is associated with hypertension related cardiovascular complications [6]. Since hypertension is a modifiable risk factor, early recognition and intervention can substantially decrease hypertension associated morbidity [7-9].

In recent years, there has been renewed interest in the field of pediatric hypertension and post-renal transplant hypertension. This has been reflected by the publication of international guidelines for the optimal diagnosis and management of hypertension in children and by a growing number of review articles on the topic of childhood hypertension post-renal transplantation [10-19].

In the adult population, the introduction of ambulatory blood pressure monitoring (ABPM) has changed the way we look at blood pressure [20]. In sharp contrast to blood pressure readings taken in the clinical setting, ABPM is much more suitable and robust in identifying those patients requiring antihypertensive treatment [21, 22].

Although the use of ABPM in the workup of children with hypertension has gained increasing attention [17, 23-27], 
there have been limited data available on the routine use of ABPM following renal transplantation [28].

This Educational Review will consist of an examination of contemporary clinical studies on the assessment of blood pressure in pediatric kidney transplant recipients. The main objective is to highlight the clinical value of ABPM after renal transplantation, thus enhancing the accuracy of blood pressure readings and facilitating clinical decision-making. Although our review is primarily based on cross-sectional studies, it also focuses on published longitudinal studies applying ABPM. Specific areas such as the pathophysiology of post-renal transplant hypertension and the treatment of pediatric hypertensive kidney transplant recipients will not be covered here since these topics have been extensively discussed in recently published review articles [13, $15,18,19]$. Although references have been selective, our review is intended to provide health professional with a concise, clear, and independent source of information.

Finally, we highlight the disadvantages of ABPM, including limited availability at certain centers and the impracticability of ABPM for patients required to travel long distances. We thus conclude that rigorous blood pressure measurements taken in the clinical setting are still useful provided that they are strictly performed according to validated protocols [12, 29-31]. In particular, it is worth pointing out that the oscillometric method of measuring blood pressure in the clinical setting is increasingly being used due in part to the widespread implementation of policies banning the use of the mercury sphygmomanometer [32, 33]. Current international guidelines still recommend the use of the auscultatory method to confirm hypertension detected by the oscillometric method $[12,29]$. There is also evidence derived from adult studies on the clinical usefulness of home blood pressure monitoring [34, 35]. In children, home blood pressure monitoring has also been recognized as a reliable tool for the assessment of blood pressure, albeit not extensively used [12]. Of note, in the clinical setting, where physicians face mounting demands on their time, the adherence to current recommendations becomes problematic $[32,33]$. Having this in mind, we have recently constructed oscillometric blood pressure tables to facilitate health provider's interpretation of oscillometric clinical blood pressure readings [36].

\section{Blood pressure measurement in the clinical setting and outside of office visits: Are they comparable?}

It should be recognized that blood pressure taken in the clinical setting is highly variable and influenced by several factors such as position of the arm and back, respiration, emotion, exercise, pain, disease, drugs as well as the circumstances of the measurement itself [37-40].

If blood pressure variability is ignored by the observer, then the risk of an erroneous diagnosis becomes high. The analysis conducted by Myers et al. showed that in adult blood pressure measurements obtained outside of the clinician's office are systematically and significantly lower than blood pressure readings obtained in the clinical setting [41]. In order to obtain a better estimation of the subject's actual underlying blood pressure, pediatric and adults guidelines acknowledge that the diagnosis of hypertension in the clinical setting should be based on multiple blood readings taken on several separate occasions [1, 3, 12, 29]. Accuracy in measuring blood pressure is therefore of the upmost importance in the correct diagnosis and proper management of hypertension. Additionally, blood pressure taken in the clinical setting is prone to clinical inertia, i.e., failure of health care providers to initiate or intensify therapy when indicated, which ultimately jeopardizes the proficiency of care provided [42].

Having briefly examined the inherent limitations of measuring blood pressure in the clinical setting, it becomes apparent that less biased and more accurate methods of representing patient's actual blood pressure patterns are needed.

The technique of non-invasive ABPM was initially conceived for evaluating antihypertensive drug efficacy [43]. An important finding derived from early studies conducted in adults was the observation of discrepancies between clinical blood pressure measurements and ABPM in a group of treated hypertensive patients [44, 45]. This observation was of clinical significance since it raised the question of whether the inconsistencies between the methods would translate into a different prediction of risk. The publication of the seminal study by Perloff et al. showed the superiority of ABPM over blood pressure measurements taken in the clinical setting in predicting cardiovascular outcomes [46]. Subsequent studies confirmed that ABPM is a better predictor of risk than BP readings taken in the clinic setting [47-51]. Over the years, the prognostic superiority of ABPM has been demonstrated both across gender and ages as well as in treated and untreated hypertensive patients with different underlying disease states.

Home blood pressure monitoring also provides more useful information than blood pressure measured in the clinical setting [52]. However, a recent meta-analysis showed that home blood pressure measurements have less sensitivity when compared to ABPM as a single method for diagnosing hypertension in adults [53]. We recognize ourselves in having limited clinical experience with the routine use of home blood pressure monitoring in our renal transplant programs and that much of our knowledge is mostly derived from the literature. An alternative worth considering is that when there is a concordance between the ABPM and home blood pressure monitoring, the latter could be appropriate for follow-up of treated hypertensive pediatric patients [12].

Several pediatric studies sought to assess whether blood pressure readings taken in the clinical setting are sufficiently reliable when compared to ABPM in adequately categorizing a recipient's blood pressure status after renal transplantation. 
Pooled data from four pediatric studies, including 188 untreated kidney transplant recipients, showed that the point estimate prevalence (adjusted Wald confidence interval) of recipients with normotension in the clinical setting, who in fact were diagnosed as having true or sustained hypertension by ABPM criteria, was $30 \%$ (95\% confidence interval 24 to $37 \%$ ) [54-57]. Also, the opposite condition, i.e., hypertension in the clinical setting while normotensive by ABPM criteria has been observed in untreated pediatric kidney transplant recipients (point estimate prevalence 9\%, 95\% confidence interval 5-13\%) [54-57]. These figures are probably an underestimation of the magnitude of the problem. The observed wide confidence interval, which precludes estimating with precision the true prevalence of the variable of interest, is likely due in part to the sample size. Nevertheless, these two conditions, i.e., masked hypertension and white-coat hypertension, respectively, can only be diagnosed by means of ABPM [58-60]. Of note, masked hypertension and whitecoat hypertension may ultimately impact the recipient's health outcomes in a negative way if they go unrecognized. In children with chronic kidney disease, masked hypertension is associated with subclinical abnormalities in cardiac structure [61]. Importantly, both in adults and children, masked hypertension should be identified and treated adequately to control hypertension [62, 63]; whereas recipients with white-coat hypertension should not receive antihypertensive treatment [1, 12, 64]. Recipients with masked hypertension should be followed regularly with ABPM to guide the management of hypertension. Since children and adults with white-coat hypertension can progress to sustained hypertension $[1,65,66]$, it is advisable to follow up with repeated ABPM to ensure timely intervention $[1,12,66]$. It should be stressed that if a patient's blood pressure values obtained in the clinical setting are in the hypertensive range and in the presence of target organ involvement from hypertension, commencement of antihypertensive treatment should not be delayed. Since the chances of obtaining a normal ABPM in this particular clinical situation are low, it is reasonable that the use of ABPM as a diagnostic tool should be deferred and applied instead for monitoring the subsequent management of hypertension.

In treated hypertensive pediatric kidney transplant recipients, we and others have observed that readings taken in the clinical setting are not a solid surrogate for ABPM in identifying true responders to antihypertensive therapy. The point estimate prevalence of uncontrolled hypertension defined upon ABPM criteria in 457 treated hypertensive recipients was $54 \%$ (95\% confidential interval 49-58\%) [54-56, 67-75]. Here, we would like to indicate that the term undertreated hypertension should be used instead of uncontrolled hypertension since in our experience, as we discuss later, the routine use of ABPM has resulted in a high prevalence of blood pressure control, whereas resistant hypertension is a rather uncommon condition [76]. Attention should also be given to the fact that over the years, the recipients' ambulatory blood pressure status has been defined in many different ways. Because of this, detailed conclusions are limited. The use of blood pressure loads, i.e., the percentage of blood pressure readings above pre-established cut-off values, as a diagnostic tool in the workup of pediatric hypertension might serve as an illustration. There is robust adult data arguing against the use of blood pressure load as a routine diagnostic tool [77, 78], and so far there is no conclusive pediatric research indicating major advantages to pediatricians in applying blood pressure loads for diagnosing hypertension or in evaluating antihypertensive efficacy. In adult studies, there is a high degree of consistency showing that mean ambulatory blood pressure values are suitable for the accurate diagnosis of hypertension and for the reliable prediction of hypertensive related organ damage [1]. In our view, the characterization of recipient's ambulatory blood pressure status in a busy clinical environment should rely on definitions that are easy to deal with unless there are compelling reasons to do otherwise. In general, complexity resists simplification, and additional investigations in this area are certainly needed.

In this section, we have shown that the application of ABPM in pediatric kidney transplant recipients provides a better estimate of true or mean blood pressure level than blood pressure readings obtained in the clinical setting. Undoubtedly, all the above-mentioned studies provide supportive evidence for a real problem when attempting to define a recipient's actual blood pressure status solely by means of blood pressure obtained in the clinical setting.

\section{Additional information provided by ABPM}

Before going further, we need to consider what has been shown on the reproducibility of ABPM. It should also be acknowledged that ABPM devices have become more precise, with measurements now more reproducible than blood pressure taken in the clinical setting [79, 80]. Validation of ABPM for application to clinical practice in pediatric kidney transplant recipients requires comparison with established office blood pressure measurement techniques, so as to determine whether the two methods used to monitor blood pressure sufficiently agree in order to be used interchangeably. Bland and Altman proposed a method for assessing agreement between two methods of measurement, based on quantifying the variation in between-differences for individual patients [81]. Repeatability is relevant to the study of method comparison because poor repeatability, i.e., considerable variation in repeated measurements on the same subject, preclude the assessment of the amount of agreement that is possible. The examination of repeatability can be approached in the same way as the assessment of agreement [81]. We examined the degree of repeatability of office and ambulatory blood 
pressure measurements in pediatric kidney transplant recipients and observed that ABPM shows a better reproducibility than blood pressure recordings taken in the clinical setting [82]. Our observation extends previous results derived from adult studies conducted in normotensive and hypertensive subjects showing that standard deviations of the mean differences, which are used as a reciprocal of blood pressure repeatability, were lower for ABPM recordings compared to office blood pressure recordings [83-86]. In order to maximize the validity and reproducibility of ambulatory blood pressure values, a recent adult guideline suggests performing two consecutive 24-h periods [87]. Clearly, this is not to be considered a requirement in daily clinical practice.

There is a diurnal rhythm of blood pressure that mainly depends on the pattern of physical activity [88]. A normal decline of blood pressure during the sleep period $\geq 10 \%$ compared with daytime blood pressure is referred to as a dipper [1]. The normal diurnal rhythm of blood pressure has been observed to be absent in some hypertensive patients and this phenomenon has been shown to be associated with increased cardiovascular morbidity and mortality [50, 89-91]. In untreated hypertensive adults, both blunted nocturnal blood pressure decline and extreme dipping are associated with worse cardiovascular prognosis as compared to normal dippers [92].

Nocturnal blood pressure and circadian rhythm is often abnormal in adult and pediatric patients with chronic kidney disease as well as after renal transplantation [93]. This should carry the implication that ABPM would offer a unique perspective for chronotherapy, i.e., bedtime dosing of antihypertensive medication in patients displaying an abnormal nondipping profile. In adults, the effect of chronotherapy remains to be elucidated [94]. In children, there are no data indicating benefit to the restoration of a normal circadian profile. In this regard, attention should also be given to the low reproducibility observed in children in the decline of blood pressure during the sleep period following renal transplantation [82].

There are, as described in the next sections, additional significant aspects from the clinical perspective.

\section{On the importance of the timely diagnosis of sustained hypertension and of achieving controlled blood pressure}

Presently, the question of controlled blood pressure is of great importance since, as previously mentioned, many treated hypertensive patients have undertreated hypertension.

In our experience, controlled blood pressure in pediatric kidney transplant recipients was more than doubled when ABPM is performed yearly, thus conveying the message to pediatric healthcare providers and researchers of the usefulness of this technique [95]. Recently, our early results were confirmed by an independent research group that in a retrospective study evaluated ambulatory blood pressure phenotypes over time in 123 pediatric and young-adult kidney transplant recipients ( 76 recipients aged $<18$ years) who underwent at least two repeated ABPM $(n=98)$ [96]. Therefore, a paradigm shift is needed to account for these results since these data are consistent with evidence showing that the use of ABPM in the management of hypertensive adult patients is of clinical value [64].

Since high blood pressure is commonly asymptomatic unless the child has severe hypertension that is left untreated [97, 98], the use of biomarkers in place of a relevant clinical outcome to which blood pressure is correlated has become commonplace (e.g., blood pressure reduction in adults instead of stroke) [1]. Additionally, a surrogate marker may be more sensitive to drugeffect change obtained over a shorter time frame. In this section, we will focus our discussion on some renal and cardiovascular surrogate markers that are routinely used in the clinical management of childhood hypertension and those that have proven prognostic value in the adult population [1].

\section{Renal function}

In adult patients with chronic kidney disease, controlled blood pressure slows the further loss of renal function [99]. Similarly, the results derived from the ESCAPE pediatric trial indicate that controlling blood pressure with a target 24-h mean arterial pressure below the 50th percentile significantly reduces the rate of progression to end-stage renal disease [100].

Although all transplant patients experience a decline in their renal function over time, adult studies have shown that for every $10 \mathrm{mmHg}$ higher systolic blood pressure graft loss is increased by $12-15 \%$ [101, 102]. Consequently, the rationale to treat hypertension after renal transplantation is not only to prevent adverse cardiovascular outcomes but also to delay the progression of allograft loss. In a 2 -year prospective interventional study aimed at improving blood pressure control by means of intensifying antihypertensive therapy and guided by applying repeated ABPM, Seeman et al. observed that in recipients with controlled blood pressure $(n=23)$, the estimated graft function remained stable whereas in recipients with uncontrolled hypertension $(n=8)$ allograft function decreased significantly over time [103].

More recently, Hamdani et al. observed that allograft function was significantly lower in recipients with sustained hypertension when compared to normotensive recipients in a large retrospective multicenter cross-sectional study including 221 participants that also used ABPM to assess blood pressure status and plasma creatinine to estimate renal function [54].

We explored the effect of hypertension, assessed by ABPM performed annually after transplantation, on the loss of renal function over a mean follow-up of 6.2 years by means of allograft function measurements, according to our local protocol, either by the renal clearance of inulin or iohexol [104]. 
Since the cohort study underwent ABPM at yearly intervals after transplantation, we assumed that the ABPM results obtained at each annual control would reflect the recipient's previous year's blood pressure status. We calculated the recipient's post-transplant cumulative exposure to hypertension by summing the number of yearly periods of uncontrolled hypertension, including new onset hypertension. We observed that there was no significant difference in the effect on glomerular filtration slope between the hypertensive recipients $(n=44)$ and recipients that were normotensive or had controlled blood pressure throughout the entire post-transplant follow-up ( $n=24)$ [104]. In the hypertensive group, the cumulative incidence of post-transplant uncontrolled hypertension represented 39\% (95\% confidence interval 31-47\%) of their follow-up period. We infer that either the magnitude or duration of exposure to hypertension in our cohort study might have been insufficient for demonstrating a negative effect on recipients' measured glomerular filtration rate or that antihypertensive treatment was indeed effective in slowing the impairment of renal allograft function [104].

\section{Left ventricular hypertrophy}

In hypertension, left ventricular hypertrophy is the heart's response to the presence of increased left ventricular load and neurohumoral stimuli, which results in an augmentation of oxygen consumption. In fact, myocardial ischemia is a hallmark of hypertensive heart disease [105]. As such, left ventricular hypertrophy is an ominous high-risk marker that demands urgent treatment. In adults, the introduction of effective long-term antihypertensive therapy resulted in a dramatic reduction in morbidity and mortality from hypertensive heart disease [106]. Left ventricular hypertrophy is also used as a surrogate outcome for cardiovascular risk in the pediatric population $[12,29]$. In children with chronic kidney disease and left ventricular hypertrophy, previous controlled studies indicate that controlled blood pressure, defined as ambulatory blood pressure levels below the 95th percentile, was associated with left ventricular mass index regression and improvement of myocardial function [100, 107]. While such data is lacking in pediatric renal transplant recipients, the presence of left ventricular hypertrophy has been well documented in this high-risk population [54, 72]. In a recently published longterm consecutive case series study, including 68 recipients that were regularly followed with ABPM from the date of transplant surgery, we reported a low prevalence of left ventricular hypertrophy at last examination $(7.6 \%, 95 \%$ confidence interval 2.5-17\%) [104]. Although a weakness of this study was the retrospective design, the low prevalence of left ventricular hypertrophy might underlay the benefit from the systematic application of ABPM at yearly intervals for the evaluation and management of post-transplant hypertension [104]. Consequently, there is a reason to believe that controlled blood pressure after renal transplantation in recipients with left ventricular hypertrophy would be associated with a decreased left ventricular mass.

\section{Intima-media thickness}

Since the introduction of the ultrasound-derived assessment of the combined intimal and media layers of the common carotid artery, the technique has gained acceptance as a marker of asymptomatic target organ damage and displayed prognostic value among subjects with hypertension [108, 109]. In the hypertensive patient, there is a positive association between systolic blood pressure and carotid intima-media thickness [110]. There is evidence of the prognostic value of carotid intima-media thickness to predict cardiovascular events both in the asymptomatic and in the diseased adults $[111,112]$. The utility of measuring carotid intima-media thickness as a primary end-point in clinical trials where the objective is to evaluate the efficacy of antihypertensive therapy has also been extensively documented [113-115]. In children, the interpretation of carotid intima-media thickness measurements has largely been facilitated by the availability of normative reference values [116]. Also, it is likely that there is an independent association between blood pressure and carotid intima-media thickness in children [117].

Based on cross-sectional data derived from a large pediatric cohort including patients with advanced chronic kidney disease as well as renal transplant recipients, Litwin et al. speculated that successful renal transplantation could partially reverse the arteriopathy associated with chronic exposure to the uremic milieu [118]. Later, the same research group substantiated this proposition in a prospective study [119]. In a previous prospective study, we examined 22 recipients over 9 years with repeated echocardiography and carotid scans in a standardized manner after transplantation [120]. Also, in accordance with our post-transplant follow-up program, all participants underwent ABPM at yearly intervals after transplantation. In this study, we did not observe any statistical evidence of systemic changes in carotid intima-media thickness over time. Additionally, the prevalence of left ventricular hypertrophy at last follow-up was low (4.5\%) [120]. Since we assumed a linear association between blood pressure and carotid intima-media thickness, we therefore infer that our results might reflect the effect of long-standing blood pressure control (point prevalence of controlled blood pressure at the last carotid scan was $82 \%$, 95\% confidence interval $56.5-$ 96.2\%) [120].

\section{Conclusions}

Hypertension-related organ damage is a chronic process that takes years to manifest. Hence, reducing the cumulative burden 
of uncontrolled hypertension and cardiovascular injury should be a priority for clinical care and research in pediatric renal transplant recipients. Here, we emphasize that the routine use of ABPM offers advantages in terms of the accurate diagnoses of hypertension and refining risk-stratification when compared to traditional blood pressure measurements taken in the clinical setting. This makes ABPM an indispensable technique in the daily clinical practice for the management of hypertension following renal transplantation. In addition, economic factors also favor ABPM, for example up to $14 \%$ savings in the cost of healthcare provision has been calculated when ABPM is incorporated in the diagnosis and treatment process of hypertension in adults [121]. Pediatric studies also suggest that diagnostic ABPM in the initial evaluation of suspected childhood hypertension may be the most economically efficient diagnostic strategy [122, 123]. We have been performing ABPM and echocardiography at yearly intervals following renal transplantation since 1998, recognizing the fact that no studies have specifically addressed the appropriateness and cost-effectiveness of this approach [82, 95, 104].

In broad terms, our cut-off points to define ambulatory hypertension are based on percentiles derived from healthy children and adolescents rather than in relation to outcomes [124]. For many years, the use of a statistical instead of an operational definition has been recognized as an important limitation in defining childhood hypertension, and progression in this area has been slow [11, 12, 29]. Although it is unknown whether differing ambulatory cut-off points below the 95th percentile would reduce post-transplant hypertensive end-organ damage with acceptable risk, our and others' data might indicate that applying the cut-off point of the 95th percentile as the upper limit of normality seems to be a prudent approach to define normotension and controlled blood pressure as well as the point at which blood pressure should be managed with antihypertensive therapy [95, 104, 107].

Finally, further larger studies capable of generating robust statistical data, i.e., knowledge, are required to investigate whether the repeated use of ABPM significantly improves the physician's decision to initiate or intensify antihypertensive therapy and to determine if this practice translates into important clinical benefits for the pediatric kidney transplant population.

\section{Key summary points}

1. Ambulatory blood pressure monitoring is more accurate than blood pressure readings taken in the clinical setting to estimate an individual's true mean blood pressure.

2. Several international professional groups have ascertained the utility of ABPM in the workup of pediatric hypertension, including post-renal transplant hypertension.
3. ABPM has the ability to identify patients with white-coat and masked hypertension and when performed at regular intervals, offers guidance for additional titration of antihypertensive medication as well as to confirm controlled hypertension.

4. Nocturnal hypertension and decreased blood pressure fall during sleep are well-described conditions after pediatric renal transplantation that can only be detected by ABPM.

\section{Multiple-choice questions (answers are provided following the reference list)}

1. All statements below regarding the use of ABPM are true except one:

a. ABPM is inferior compared to blood pressure measurements taken in the clinical setting for improving a subject's risk stratification.

b. ABPM identifies patients with white-coat hypertension.

c. ABPM identifies patients with masked hypertension.

d. ABPM provides a better estimate of a subject's true mean blood pressure than blood pressure measurements taken in the clinical setting.

2. What is the best method of measuring blood pressure for the diagnosis and treatment monitoring of hypertension in renal transplant recipients?

a. Home blood pressure measurements.

b. ABPM.

c. Blood pressure measurements taken in the clinical setting.

d. All of them are alike.

3. What should be done in a recipient with hypertension that is diagnosed in the clinical setting and who has verified hypertensive-related organ damage?

a. Confirm hypertension by ABPM.

b. Start antihypertensive treatment without delay and monitoring treatment with ABPM.

c. After confirming hypertension by means of ABPM, treatment monitor should only rely upon blood pressure measurements taken in the clinical setting.

d. Answers a) and c) are correct.

4. In treated hypertensive renal transplant recipients with ambulatory controlled blood pressure:

a. The annual loss of renal allograft function is expected to be similar to normotensive recipients.

b. In hypertensive recipients with initially diagnosed left ventricular hypertrophy it is most likely to observe a 
regression of left ventricular mass under successfully long-term controlled blood pressure.

c. Uncontrolled hypertension has been shown to be associated with increased carotid intima-media thickness.

d. All answers are correct.

Author contributions Dr. Krmar performed a comprehensive literature search, did descriptive statistics, and drafted the manuscript. Dr. Ferraris revised the manuscript critically for important intellectual content. Dr. Krmar and Dr. Ferraris gave final approval of the version of the manuscript to be submitted.

\section{Compliance with ethical standards}

Conflict of interest All authors have reported that they have no relationships relevant to the content of this paper to disclose.

Open Access This article is distributed under the terms of the Creative Commons Attribution 4.0 International License (http:// creativecommons.org/licenses/by/4.0/), which permits unrestricted use, distribution, and reproduction in any medium, provided you give appropriate credit to the original author(s) and the source, provide a link to the Creative Commons license, and indicate if changes were made.

\section{References}

1. Mancia G, Fagard R, Narkiewicz K, Redon J, Zanchetti A, Bohm M, Christiaens T, Cifkova R, De Backer G, Dominiczak A, Galderisi M, Grobbee DE, Jaarsma T, Kirchhof P, Kjeldsen SE, Laurent S, Manolis AJ, Nilsson PM, Ruilope LM, Schmieder RE, Sirnes PA, Sleight P, Viigimaa M, Waeber B, Zannad F, Task Force M (2013) 2013 ESH/ESC guidelines for the management of arterial hypertension: the task force for the management of arterial hypertension of the European Society of Hypertension (ESH) and of the European Society of Cardiology (ESC). J Hypertens 31:1281-1357

2. James PA, Oparil S, Carter BL, Cushman WC, DennisonHimmelfarb C, Handler J, Lackland DT, LeFevre ML, MacKenzie TD, Ogedegbe O, Smith SC Jr, Svetkey LP, Taler SJ, Townsend RR, Wright JT Jr, Narva AS, Ortiz E (2014) 2014 evidence-based guideline for the management of high blood pressure in adults: report from the panel members appointed to the eighth joint National Committee (JNC 8). JAMA 311:507-520

3. Siu AL, Force USPST (2015) Screening for high blood pressure in adults: U.S. preventive services task force recommendation statement. Ann Intern Med 163:778-786

4. Go AS, Chertow GM, Fan D, McCulloch CE, Hsu CY (2004) Chronic kidney disease and the risks of death, cardiovascular events, and hospitalization. N Engl J Med 351:1296-1305

5. Bertram JF, Goldstein SL, Pape L, Schaefer F, Shroff RC, Warady BA (2016) Kidney disease in children: latest advances and remaining challenges. Nat Rev Nephrol 12:182-191

6. Al Nasser Y, Moura MC, Mertens L, McCrindle BW, Parekh RS, Ng VL, Church PC, Mouzaki M (2016) Subclinical cardiovascular changes in pediatric solid organ transplant recipients: a systematic review and meta-analysis. Pediatr Transplant 20:530-539

7. Thomopoulos C, Parati G, Zanchetti A (2014) Effects of blood pressure lowering on outcome incidence in hypertension: 3. Effects in patients at different levels of cardiovascular risk-overview and meta-analyses of randomized trials. J Hypertens 32:2305-2314
8. Thomopoulos C, Parati G, Zanchetti A (2014) Effects of blood pressure lowering on outcome incidence in hypertension: 2 . Effects at different baseline and achieved blood pressure levelsoverview and meta-analyses of randomized trials. J Hypertens 32: 2296-2304

9. Thomopoulos C, Parati G, Zanchetti A (2014) Effects of blood pressure lowering on outcome incidence in hypertension. 1. Overview, meta-analyses, and meta-regression analyses of randomized trials. J Hypertens 32:2285-2295

10. Steinberger J, Daniels SR, Hagberg N, Isasi CR, Kelly AS, LloydJones D, Pate RR, Pratt C, Shay CM, Towbin JA, Urbina E, Van Horn LV, Zachariah JP, American Heart Association Atherosclerosis H, Obesity in the Young Committee of the Council on Cardiovascular Disease in the Y, Council on C, Stroke N, Council on E, Prevention, Council on Functional G, Translational B, Stroke C (2016) Cardiovascular health promotion in children: challenges and opportunities for 2020 and beyond: a scientific statement from the American Heart Association. Circulation 134:e236-e255

11. Flynn JT (2014) Pediatric ambulatory blood pressure monitoring grows up. J Am Soc Hypertens 8:668-669

12. Lurbe E, Agabiti-Rosei E, Cruickshank JK, Dominiczak A, Erdine S, Hirth A, Invitti C, Litwin M, Mancia G, Pall D, Rascher W, Redon J, Schaefer F, Seeman T, Sinha M, Stabouli S, Webb NJ, Wuhl E, Zanchetti A (2016) 2016 European Society of Hypertension guidelines for the management of high blood pressure in children and adolescents. J Hypertens 34:1887-1920

13. Seeman T (2009) Hypertension after renal transplantation. Pediatr Nephrol 24:959-972

14. Seeman T (2012) Ambulatory blood pressure monitoring in pediatric renal transplantation. Curr Hypertens Rep 14:608-618

15. Weir MR, Burgess ED, Cooper JE, Fenves AZ, Goldsmith D, McKay D, Mehrotra A, Mitsnefes MM, Sica DA, Taler SJ (2015) Assessment and management of hypertension in transplant patients. J Am Soc Nephrol 26:1248-1260

16. Filler G, Melk A, Marks SD (2016) Practice recommendations for the monitoring of renal function in pediatric non-renal organ transplant recipients. Pediatr Transplant 20:352-363

17. Hooper DK, Mitsnefes M (2016) A systems-based approach to managing blood pressure in children following kidney transplantation. Pediatr Nephrol 31:1593-1604

18. Dionne JM, Abitbol CL, Flynn JT (2012) Hypertension in infancy: diagnosis, management and outcome. Pediatr Nephrol 27:17-32

19. Charnaya O, Moudgil A (2017) Hypertension in the pediatric kidney transplant recipient. Front Pediatr 5:86

20. McCain J (2016) William B. White explains the changes in the way we look at blood pressure: which numbers matter most-and why can they be deceptive? P T 41:573-580

21. Gerin W, Schwartz JE, Devereux RB, Goyal T, Shimbo D, Ogedegbe G, Rieckmann N, Abraham D, Chaplin W, Burg M, Jhulani J, Pickering TG (2006) Superiority of ambulatory to physician blood pressure is not an artifact of differential measurement reliability. Blood Press Monit 11:297-301

22. Pickering TG, Shimbo D, Haas D (2006) Ambulatory bloodpressure monitoring. N Engl J Med 354:2368-2374

23. Flynn JT (2012) Ambulatory blood pressure monitoring should be routinely performed after pediatric renal transplantation. Pediatr Transplant 16:533-536

24. Graves JW, Althaf MM (2006) Utility of ambulatory blood pressure monitoring in children and adolescents. Pediatr Nephrol 21: $1640-1652$

25. Gavrilovici C, Goldsmith DJ, Reid C, Gubeth-Tatomir P, Covic A (2004) What is the role of ambulatory BP monitoring in pediatric nephrology? J Nephrol 17:642-652 
26. Mitsnefes MM, Portman RJ (2003) Ambulatory blood pressure monitoring in pediatric renal transplantation. Pediatr Transplant 7:86-92

27. Bald M (2002) Ambulatory blood pressure monitoring in children and adolescents. Current insights into a new technique. Minerva Pediatr 54:13-24

28. Peterson CG, Miyashita Y (2017) The use of ambulatory blood pressure monitoring as standard of Care in Pediatrics. Front Pediatr 5:153

29. National High Blood Pressure Education Program Working Group on High Blood Pressure in C, Adolescents (2004) The fourth report on the diagnosis, evaluation, and treatment of high blood pressure in children and adolescents. Pediatrics 114:555-576

30. Ogedegbe G, Pickering T (2010) Principles and techniques of blood pressure measurement. Cardiol Clin 28:571-586

31. Stolarz-Skrzypek K, Thijs L, Wizner B, Richart T, Ogedegbe G, Li Y, Hansen TW, Boggia J, Kikuya M, Kuznetsova T, Wang J, Lurbe E, Imai Y, Kawecka-Jaszcz K, Staessen JA (2010) From pioneering to implementing automated blood pressure measurement in clinical practice: Thomas Pickering's legacy. Blood Press Monit 15:72-81

32. Stergiou GS, Boubouchairopoulou N, Kollias A (2017) Accuracy of automated blood pressure measurement in children: evidence, issues, and perspectives. Hypertension 69:1000-1006

33. Stergiou GS, Kollias A, Boubouchairopoulou N, Ntineri A, O'Brien E (2017) Evidence on the accuracy of automated blood pressure monitors in children: quantity versus quality. J Hypertens 35:896-897

34. Pickering TG, Miller NH, Ogedegbe G, Krakoff LR, Artinian NT, Goff D, American Heart A, American Society of H, Preventive Cardiovascular Nurses A (2008) Call to action on use and reimbursement for home blood pressure monitoring: a joint scientific statement from the American Heart Association, American society of hypertension, and preventive cardiovascular nurses association. Hypertension 52:10-29

35. Parati G, Stergiou GS, Asmar R, Bilo G, de Leeuw P, Imai Y, Kario K, Lurbe E, Manolis A, Mengden T, O’Brien E, Ohkubo T, Padfield P, Palatini P, Pickering T, Redon J, Revera M, Ruilope LM, Shennan A, Staessen JA, Tisler A, Waeber B, Zanchetti A, Mancia G, Monitoring ESHWGoBP (2008) European Society of Hypertension guidelines for blood pressure monitoring at home: a summary report of the second international consensus conference on home blood pressure monitoring. J Hypertens 26:1505-1526

36. Krmar RT, Holtback U, Bergh A, Svensson E, Wuhl E (2015) Oscillometric casual blood pressure normative standards for Swedish children using ABPM to exclude casual hypertension. Am J Hypertens 28:459-468

37. Armitage P, Fox W, Rose GA, Tinker CM (1966) The variability of measurements of casual blood pressure. II. Survey experience. Clin Sci 30:337-344

38. Armitage P, Rose GA (1966) The variability of measurements of casual blood pressure. I. A laboratory study. Clin Sci 30:325-335

39. Cushman WC, Cooper KM, Horne RA, Meydrech EF (1990) Effect of back support and stethoscope head on seated blood pressure determinations. Am J Hypertens 3:240-241

40. Pickering TG (1993) Blood pressure variability and ambulatory monitoring. Curr Opin Nephrol Hypertens 2:380-385

41. Myers MG (2014) Replacing manual sphygmomanometers with automated blood pressure measurement in routine clinical practice. Clin Exp Pharmacol Physiol 41:46-53

42. Phillips LS, Branch WT, Cook CB, Doyle JP, El-Kebbi IM, Gallina DL, Miller CD, Ziemer DC, Barnes CS (2001) Clinical inertia. Ann Intern Med 135:825-834

43. Kain HK, Hinman AT, Sokolow M (1964) Arterial blood pressure measurements with a portable recorder in hypertensive patients. I.
Variability and correlation with "casual" pressures. Circulation 30: 882-892

44. Millar-Craig MW, Mann S, Balasubramanian V, Altman D, Raftery EB (1979) The acute and chronic effects of oxprenolol on ambulatory blood pressure and heart rate in essential hypertension [proceedings]. Br J Clin Pharmacol 8:389P

45. Balasubramanian V, Mann S, Millar-Craig MW, Raftery EB (1979) Effect of labetalol in hypertension during exercise and postural changes. Br J Clin Pharmacol 8(Suppl 2):95S-100S

46. Perloff D, Sokolow M, Cowan R (1983) The prognostic value of ambulatory blood pressures. JAMA 249:2792-2798

47. Khattar RS, Senior R, Lahiri A (1998) Cardiovascular outcome in white-coat versus sustained mild hypertension: a 10-year followup study. Circulation 98:1892-1897

48. Ohkubo T, Imai Y, Tsuji I, Nagai K, Watanabe N, Minami N, Itoh O, Bando T, Sakuma M, Fukao A, Satoh H, Hisamichi S, Abe K (1997) Prediction of mortality by ambulatory blood pressure monitoring versus screening blood pressure measurements: a pilot study in Ohasama. J Hypertens 15:357-364

49. Redon J, Campos C, Narciso ML, Rodicio JL, Pascual JM, Ruilope LM (1998) Prognostic value of ambulatory blood pressure monitoring in refractory hypertension: a prospective study. Hypertension 31:712-718

50. Staessen JA, Thijs L, Fagard R, O'Brien ET, Clement D, de Leeuw PW, Mancia G, Nachev C, Palatini P, Parati G, Tuomilehto J, Webster J (1999) Predicting cardiovascular risk using conventional vs ambulatory blood pressure in older patients with systolic hypertension. Systolic hypertension in Europe trial investigators. JAMA 282:539-546

51. Verdecchia P, Schillaci G, Borgioni C, Ciucci A, Gattobigio R, Zampi I, Santucci A, Santucci C, Reboldi G, Porcellati C (1996) Prognostic value of left ventricular mass and geometry in systemic hypertension with left ventricular hypertrophy. Am J Cardiol 78:197-202

52. Stergiou GS, Bliziotis IA (2011) Home blood pressure monitoring in the diagnosis and treatment of hypertension: a systematic review. Am J Hypertens 24:123-134

53. Hodgkinson J, Mant J, Martin U, Guo B, Hobbs FD, Deeks JJ, Heneghan C, Roberts N, McManus RJ (2011) Relative effectiveness of clinic and home blood pressure monitoring compared with ambulatory blood pressure monitoring in diagnosis of hypertension: systematic review. BMJ 342:d3621

54. Hamdani G, Nehus EJ, Hanevold CD, Sebestyen Van Sickle J, Woroniecki R, Wenderfer SE, Hooper DK, Blowey D, Wilson A, Warady BA, Mitsnefes MM (2017) Ambulatory blood pressure, left ventricular hypertrophy, and allograft function in children and young adults after kidney transplantation. Transplantation 101:150-156

55. Hamdani G, Nehus EJ, Hooper DK, Mitsnefes MM (2016) Masked hypertension and allograft function in pediatric and young adults kidney transplant recipients. Pediatr Transplant 20:1026-1031

56. Bulum B, Ozcakar ZB, Kavaz A, Tutar E, Ekim M, Yalcinkaya F (2015) Hypertension in children after renal transplantation. Pediatr Int 57:1138-1142

57. Tainio J, Qvist E, Miettinen J, Holtta T, Pakarinen M, Jahnukainen T, Jalanko H (2015) Blood pressure profiles 5 to 10 years after transplant in pediatric solid organ recipients. J Clin Hypertens (Greenwich) 17:154-161

58. Pickering TG, Davidson K, Gerin W, Schwartz JE (2002) Masked hypertension. Hypertension 40:795-796

59. Pickering TG, James GD, Boddie C, Harshfield GA, Blank S, Laragh JH (1988) How common is white coat hypertension? JAMA 259:225-228

60. Mancia G (2002) Reversed white-coat hypertension: definition, mechanisms and prognostic implications. J Hypertens 20:579 581

61. Mitsnefes M, Flynn J, Cohn S, Samuels J, Blydt-Hansen T, Saland J, Kimball T, Furth S, Warady B, Group CKS (2010) Masked 
hypertension associates with left ventricular hypertrophy in children with CKD. J Am Soc Nephrol 21:137-144

62. Liu JE, Roman MJ, Pini R, Schwartz JE, Pickering TG, Devereux RB (1999) Cardiac and arterial target organ damage in adults with elevated ambulatory and normal office blood pressure. Ann Intern Med 131:564-572

63. Lurbe E, Torro I, Alvarez V, Nawrot T, Paya R, Redon J, Staessen JA (2005) Prevalence, persistence, and clinical significance of masked hypertension in youth. Hypertension 45:493-498

64. Mancia G, Verdecchia P (2015) Clinical value of ambulatory blood pressure: evidence and limits. Circ Res 116:1034-1045

65. Huang Y, Huang W, Mai W, Cai X, An D, Liu Z, Huang H, Zeng J, $\mathrm{Hu}$ Y, Xu D (2017) White-coat hypertension is a risk factor for cardiovascular diseases and total mortality. J Hypertens 35:677688

66. Westerståhl M, Forss M, Persson L, Bouma K, Gustavsson T, Wühl E, Krmar RT (2017) Hypertension outcomes and cardiovascular status in young adults with childhood-diagnosed white coat hypertension. Arch Dis Child. doi:10.1136/archdischild-2017313298

67. Gulhan B, Topaloglu R, Karabulut E, Ozaltin F, Aki FT, Bilginer Y, Besbas N (2014) Post-transplant hypertension in pediatric kidney transplant recipients. Pediatr Nephrol 29:1075-1080

68. Degi A, Kerti A, Cseprekal O, Kis E, Sallay P, Szabo AJ, Reusz GS (2013) Ambulatory arterial stiffness index in children after kidney transplantation. Pediatr Transplant 17:598-604

69. Paripovic D, Kostic M, Spasojevic B, Kruscic D, Peco-Antic A (2010) Masked hypertension and hidden uncontrolled hypertension after renal transplantation. Pediatr Nephrol 25:1719-1724

70. Sethna CB, Leonard MB, Gallagher PR, Meyers KE (2009) Serum adiponectin levels and ambulatory blood pressure monitoring in pediatric renal transplant recipients. Transplantation 88: 1030-1037

71. Ferraris JR, Ghezzi L, Waisman G, Krmar RT (2007) ABPM vs office blood pressure to define blood pressure control in treated hypertensive paediatric renal transplant recipients. Pediatr Transplant 11:24-30

72. Seeman T, Simkova E, Kreisinger J, Vondrak K, Dusek J, Gilik J, Feber J, Dvorak P, Janda J (2006) Control of hypertension in children after renal transplantation. Pediatr Transplant 10:316-322

73. Seeman T, Dusek J, Vondrak K, Simkova E, Kreisinger J, Feber J, Janda J (2004) Ambulatory blood pressure monitoring in children after renal transplantation. Transplant Proc 36:1355-1356

74. Morgan H, Khan I, Hashmi A, Hebert D, McCrindle BW, Balfe JW (2001) Ambulatory blood pressure monitoring after renal transplantation in children. Pediatr Nephrol 16:843-847

75. Giordano U, Matteucci MC, Calzolari A, Turchetta A, Rizzoni G, Alpert BS (2000) Ambulatory blood pressure monitoring in children with aortic coarctation and kidney transplantation. J Pediatr 136:520-523

76. Halling SE, Asling-Monemi K, Herthelius M, Celsi G, Vavilis G, Kuru NK, Efvergren M, Krmar RT (2010) Minoxidil therapy in children and young adult patients with renal disease and refractory hypertension: value when multidrug regimens have failed to achieve blood pressure control. J Hum Hypertens 24:552-554

77. Li Y, Thijs L, Boggia J, Asayama K, Hansen TW, Kikuya M, Bjorklund-Bodegard K, Ohkubo T, Jeppesen J, Torp-Pedersen C, Dolan E, Kuznetsova T, Stolarz-Skrzypek K, Tikhonoff V, Malyutina S, Casiglia E, Nikitin Y, Lind L, Sandoya E, Kawecka-Jaszcz K, Filipovsky J, Imai Y, Ibsen H, O’Brien E, Wang J, Staessen JA, International Database on Ambulatory blood pressure in relation to Cardiovascular Outcomes I (2014) Blood pressure load does not add to ambulatory blood pressure level for cardiovascular risk stratification. Hypertension 63:925-933
78. Reboldi G, Angeli F, Verdecchia P (2014) Interpretation of ambulatory blood pressure profile for risk stratification: keep it simple. Hypertension 63:913-914

79. Lurbe E, Redon J (2002) Reproducibility and validity of ambulatory blood pressure monitoring in children. Am J Hypertens 15: 69S-73S

80. de la Sierra A, Banegas JR, Divison JA, Gorostidi M, Vinyoles E, de la Cruz JJ, Segura J, Ruilope LM (2016) Ambulatory blood pressure in hypertensive patients with inclusion criteria for the SPRINT trial. J Am Soc Hypertens 10(947-953):e945

81. Bland JM, Altman DG (1986) Statistical methods for assessing agreement between two methods of clinical measurement. Lancet $1: 307-310$

82. Krmar RT, Berg UB (2005) Long-term reproducibility of routine ambulatory blood pressure monitoring in stable pediatric renal transplant recipients. Am J Hypertens 18:1408-1414

83. Mansoor GA, McCabe EJ, White WB (1994) Long-term reproducibility of ambulatory blood pressure. J Hypertens 12:703-708

84. Asagami T, Kushiro T, Inoue J, Kanmatsuse K (1996) Long-term reproducibility and usefulness of daytime recording of noninvasive 24-hour ambulatory blood pressure monitoring in borderline hypertension: a two-year follow-up study. Clin Exp Hypertens 18: 637-657

85. Wendelin-Saarenhovi M, Isoaho R, Hartiala J, Helenius H, Kivela SL, Hietanen E (2001) Long-term reproducibility of ambulatory blood pressure in unselected elderly subjects. Clin Physiol 21: 316-322

86. Trazzi S, Mutti E, Frattola A, Imholz B, Parati G, Mancia G (1991) Reproducibility of non-invasive and intra-arterial blood pressure monitoring: implications for studies on antihypertensive treatment. J Hypertens 9:115-119

87. Hermida RC, Ayala DE, Fontao MJ, Mojon A, Fernandez JR (2013) Ambulatory blood pressure monitoring: importance of sampling rate and duration- 48 versus 24 hours-on the accurate assessment of cardiovascular risk. Chronobiol Int 30:55-67

88. Clark LA, Denby L, Pregibon D, Harshfield GA, Pickering TG, Blank S, Laragh JH (1987) A quantitative analysis of the effects of activity and time of day on the diurnal variations of blood pressure. J Chronic Dis 40:671-681

89. Verdecchia P, Angeli F, Cavallini C (2007) Ambulatory blood pressure for cardiovascular risk stratification. Circulation 115: 2091-2093

90. Ingelsson E, Bjorklund-Bodegard K, Lind L, Arnlov J, Sundstrom J (2006) Diurnal blood pressure pattern and risk of congestive heart failure. JAMA 295:2859-2866

91. Ohkubo T, Hozawa A, Yamaguchi J, Kikuya M, Ohmori K, Michimata M, Matsubara M, Hashimoto J, Hoshi H, Araki T, Tsuji I, Satoh H, Hisamichi S, Imai Y (2002) Prognostic significance of the nocturnal decline in blood pressure in individuals with and without high 24-h blood pressure: the Ohasama study. J Hypertens 20:2183-2189

92. Salles GF, Reboldi G, Fagard RH, Cardoso CR, Pierdomenico SD, Verdecchia P, Eguchi K, Kario K, Hoshide S, Polonia J, de la Sierra A, Hermida RC, Dolan E, O’Brien E, Roush GC, Investigators A-H (2016) Prognostic effect of the nocturnal blood pressure fall in hypertensive patients: the ambulatory blood pressure collaboration in patients with hypertension $(\mathrm{ABC}-\mathrm{H})$ metaanalysis. Hypertension 67:693-700

93. Kimura G (2008) Kidney and circadian blood pressure rhythm. Hypertension 51:827-828

94. Zhao P, Xu P, Wan C, Wang Z (2011) Evening versus morning dosing regimen drug therapy for hypertension. Cochrane Database Syst Rev:CD004184

95. Krmar RT, Berg UB (2008) Blood pressure control in hypertensive pediatric renal transplants: role of repeated ABPM following transplantation. Am J Hypertens 21:1093-1099 
96. Hamdani G, Nehus EJ, Hanevold CD, VanSickle JS, Hooper DK, Blowey D, Warady BA, Mitsnefes MM (2017) Ambulatory blood pressure control in children and young adults after kidney transplantation. Am J Hypertens. doi:10.1093/ajh/hpx092

97. Still JL, Cottom D (1967) Severe hypertension in childhood. Arch Dis Child 42:34-39

98. Chrispin AR, Scatliff JH (1973) Systemic hypertension in childhood. Pediatr Radiol 1:75-86

99. Young JH, Klag MJ, Muntner P, Whyte JL, Pahor M, Coresh J (2002) Blood pressure and decline in kidney function: findings from the systolic hypertension in the elderly program (SHEP). J Am Soc Nephrol 13:2776-2782

100. Group ET, Wuhl E, Trivelli A, Picca S, Litwin M, Peco-Antic A, Zurowska A, Testa S, Jankauskiene A, Emre S, Caldas-Afonso A, Anarat A, Niaudet P, Mir S, Bakkaloglu A, Enke B, Montini G, Wingen AM, Sallay P, Jeck N, Berg U, Caliskan S, Wygoda S, Hohbach-Hohenfellner K, Dusek J, Urasinski T, Arbeiter K, Neuhaus T, Gellermann J, Drozdz D, Fischbach M, Moller K, Wigger M, Peruzzi L, Mehls O, Schaefer F (2009) Strict bloodpressure control and progression of renal failure in children. $\mathrm{N}$ Engl J Med 361:1639-1650

101. Mange KC, Cizman B, Joffe M, Feldman HI (2000) Arterial hypertension and renal allograft survival. JAMA 283:633-638

102. Kasiske BL, Anjum S, Shah R, Skogen J, Kandaswamy C, Danielson B, O'Shaughnessy EA, Dahl DC, Silkensen JR, Sahadevan M, Snyder JJ (2004) Hypertension after kidney transplantation. Am J Kidney Dis 43:1071-1081

103. Seeman T, Simkova E, Kreisinger J, Vondrak K, Dusek J, Gilik J, Dvorak P, Janda J (2007) Improved control of hypertension in children after renal transplantation: results of a two-yr interventional trial. Pediatr Transplant 11:491-497

104. Cameron C, Vavilis G, Kowalski J, Tyden G, Berg UB, Krmar RT (2014) An observational cohort study of the effect of hypertension on the loss of renal function in pediatric kidney recipients. Am J Hypertens 27:579-585

105. Diez J, Frohlich ED (2010) A translational approach to hypertensive heart disease. Hypertension 55:1-8

106. Kannel WB (1991) Left ventricular hypertrophy as a risk factor: the Framingham experience. J Hypertens Suppl 9:S3-8; discussion S8-9

107. Matteucci MC, Chinali M, Rinelli G, Wuhl E, Zurowska A, Charbit M, Pongiglione G, Schaefer F, Group ET (2013) Change in cardiac geometry and function in CKD children during strict BP control: a randomized study. Clin J Am Soc Nephrol 8: 203-210

108. Pignoli P, Tremoli E, Poli A, Oreste P, Paoletti R (1986) Intimal plus medial thickness of the arterial wall: a direct measurement with ultrasound imaging. Circulation 74:1399-1406

109. Bots ML, Sutton-Tyrrell K (2012) Lessons from the past and promises for the future for carotid intima-media thickness. J Am Coll Cardiol 60:1599-1604

110. Bots ML, Witteman JC, Grobbee DE (1993) Carotid intima-media wall thickness in elderly women with and without atherosclerosis of the abdominal aorta. Atherosclerosis 102:99-105

111. Lorenz MW, Markus HS, Bots ML, Rosvall M, Sitzer M (2007) Prediction of clinical cardiovascular events with carotid intimamedia thickness: a systematic review and meta-analysis. Circulation 115:459-467

112. Bots ML, Groenewegen KA, Anderson TJ, Britton AR, Dekker JM, Engstrom G, Evans GW, de Graaf J, Grobbee DE, Hedblad B, Hofman A, Holewijn S, Ikeda A, Kavousi M, Kitagawa K, Kitamura A, Ikram MA, Lonn EM, Lorenz MW, Mathiesen EB, Nijpels G, Okazaki S, O’Leary DH, Polak JF, Price JF, Robertson
C, Rembold CM, Rosvall M, Rundek T, Salonen JT, Sitzer M, Stehouwer CD, Franco OH, Peters SA, den Ruijter HM (2014) Common carotid intima-media thickness measurements do not improve cardiovascular risk prediction in individuals with elevated blood pressure: the USE-IMT collaboration. Hypertension 63: 1173-1181

113. Hedblad B, Wikstrand J, Janzon L, Wedel H, Berglund G (2001) Low-dose metoprolol CR/XL and fluvastatin slow progression of carotid intima-media thickness: main results from the Beta-blocker cholesterol-lowering asymptomatic plaque study (BCAPS). Circulation 103:1721-1726

114. Simon A, Gariepy J, Moyse D, Levenson J (2001) Differential effects of nifedipine and co-amilozide on the progression of early carotid wall changes. Circulation 103:2949-2954

115. Zanchetti A, Bond MG, Hennig M, Neiss A, Mancia G, Dal Palu C, Hansson L, Magnani B, Rahn KH, Reid JL, Rodicio J, Safar M, Eckes L, Rizzini P, European Lacidipine Study on Atherosclerosis i (2002) Calcium antagonist lacidipine slows down progression of asymptomatic carotid atherosclerosis: principal results of the European Lacidipine study on atherosclerosis (ELSA), a randomized, double-blind, long-term trial. Circulation 106:2422-2427

116. Doyon A, Kracht D, Bayazit AK, Deveci M, Duzova A, Krmar RT, Litwin M, Niemirska A, Oguz B, Schmidt BM, Sozeri B, Querfeld U, Melk A, Schaefer F, Wuhl E, Consortium CS (2013) Carotid artery intima-media thickness and distensibility in children and adolescents: reference values and role of body dimensions. Hypertension 62:550-556

117. Day TG, Park M, Kinra S (2017) The association between blood pressure and carotid intima-media thickness in children: a systematic review. Cardiol Young:1-11

118. Litwin M, Wuhl E, Jourdan C, Trelewicz J, Niemirska A, Fahr K, Jobs K, Grenda R, Wawer ZT, Rajszys P, Troger J, Mehls O, Schaefer F (2005) Altered morphologic properties of large arteries in children with chronic renal failure and after renal transplantation. J Am Soc Nephrol 16:1494-1500

119. Litwin M, Wuhl E, Jourdan C, Niemirska A, Schenk JP, Jobs K, Grenda R, Wawer ZT, Rajszys P, Mehls O, Schaefer F (2008) Evolution of large-vessel arteriopathy in paediatric patients with chronic kidney disease. Nephrol Dial Transplant 23:2552-2557

120. Balzano R, Lindblad YT, Vavilis G, Jogestrand T, Berg UB, Krmar RT (2011) Use of annual ABPM, and repeated carotid scan and echocardiography to monitor cardiovascular health over nine $\mathrm{yr}$ in pediatric and young adult renal transplant recipients. Pediatr Transplant 15:635-641

121. Krakoff LR (2006) Cost-effectiveness of ambulatory blood pressure: a reanalysis. Hypertension 47:29-34

122. Swartz SJ, Srivaths PR, Croix B, Feig DI (2008) Costeffectiveness of ambulatory blood pressure monitoring in the initial evaluation of hypertension in children. Pediatrics 122:11771181

123. Davis ML, Ferguson MA, Zachariah JP (2014) Clinical predictors and impact of ambulatory blood pressure monitoring in pediatric hypertension referrals. J Am Soc Hypertens 8:660-667

124. Wuhl E, Witte K, Soergel M, Mehls O, Schaefer F, German Working Group on Pediatric H (2002) Distribution of 24-h ambulatory blood pressure in children: normalized reference values and role of body dimensions. J Hypertens 20:1995-2007

\section{Answers to questions}

1. a; 2. b; 3. b; 4. d 